\title{
The Effect of Prone Position Versus Supine Position on Oxygen Saturation among Jordanian Preterm with Respiratory Distress Syndrome
}

\author{
Almomani J* \\ Mutah University, Jordan
}

*Corresponding author: Jumana Almomani, Mutah University, Jordan, Tel: 962772487574; Email: jujo420@yahoo.com

\section{Research Article}

Volume 4 Issue 3

Received Date: April 15, 2020

Published Date: May 18, 2020

DOI: $10.23880 /$ nhij-16000222

\section{Abstract}

Background: The prone position for preterm neonates had been played an important role to improve physiological statues for respiratory distress syndrome diseases. Prone position correlates with improvement of diaphragmatic movement or pulmonary perfusion especially in preterm's neonates.

Objective: To assess the oxygen saturation on Jordanian preterm neonates with respiratory distress syndrome, during prone position comparing to supine position.

Method: This pilot study is conducted with randomized clinical trial of thirty preterm neonates (age < 28days of gestations) in nursery ward at Queen Rania hospital during two months from 25 July-25 September 2015. Supine-prone cycle was applied for one time, where preterm's were placed first in supine position for total 2 hours then followed by prone position for 2 hours. Oxygen saturation was measured at 30 minutes intervals, corresponding to 8 samples for 4 hours. The data were recorded using the pulse oximeter by same staff nurse.

Results: At the end of the last 2 hour s of supine position, $\mathrm{O}_{2}$ saturation mean \& SD $(96.3+1.5)$ and at the end of last hour on prone position was $(98.53+1.506)$. Independent sample $t$ test revealed that there is significant differences between prone and supine position on this duration time, the result showed $\mathrm{O}_{2}$ saturation in prone position significant $(\mathrm{t}=4.35, \mathrm{P}<0.05)$.

Conclusion: The prone position showed an effect on preterm babies diagnosed with respiratory distress syndrome diseases, comparing to the supine position. This maneuver considers safe method that decreases the complication in respiratory distress syndrome diseases on preterm neonates.

Keywords: Respiratory Distress Syndrome; Preterm; Prone position

\section{Introduction}

Respiratory distress syndrome still considered the most causes of neonatal mortality and morbidity especially in preterm neonates, despites its management had developed over the past years [1]. In Jordan, its account 53.3 of early, late and almost of neonatal death according to the national prospective study in Jordan [2].
Moreover , studies showed that $92 \%$ of neonates born 24-25 weeks of gestation, $88 \%$ of neonates born 26-27 weeks of gestation, $76 \%$ of neonates born 28-29 weeks of gestation and $57 \%$ of neonates born at $30-31$ weeks gestation present with this disease [3].

Nursing position can affect physiological statues of respiratory system especially in preterm neonates; the 
mechanism in putting neonates in prone position it is not only affect the chest mechanisms, but also its correlate to the improvement in tidal volume distribution and improve pulmonary perfusion that affect overall alveolar ventilation/ perfusion mismatch [4].

Effective prone position showed an enhancement not only the respiratory status or peripheral $\mathrm{O}_{2}$ saturation and arterial blood gases ,but also many studies showed effect on heart rates fluctuations in preterm infants [5].

In addition, prone position among preterm's had showed greater sleep efficiency and fewer obstructive sleep apnea as another benefit of this position $[6,7]$.

The aim of this study is to show the effect of prone position on preterm baby comparing to supine position in order to improve oxygen saturation in Jordanian preterm neonates with respiratory distress syndrome, since up to the researcher knowledge no studies were published in Jordan to show this significant effect of this nursing position.

\section{Methodology}

After legal and ethical approval of neonatal specialist health teams and agreement of institutional reviewed board of Royal medical services RMS in Jordan, this pilot study was conducted of 30 preterm neonates selected in randomize clinical trial in neonatal ward at Queen Rania hospital of children.

The inclusion criteria was; preterm neonates who's lived less than 28 days of their gestational age, diagnosed with mild, moderate, or severe respiratory distress syndrome RDS, they were on nasal CPAP, ventilation supports and on nasal canula according the hospital policy for apply oxygen supports.

The researcher exclude from the study; preterm neonates with major malformations or preterm's neonates with congenital heart diseases in order to minimize any risks. The study had conducted approximately two months in duration from the 25 of July till 25 September/ 2015, the preterm's parents were informed about the study, one staff nurse were assigned in this study for oxygen saturation documentations, she was oriented about the criteria of this study prior she started to collect the samples. The staff nurse had six years' experience in nursery filed, and she applied that during her routine care to the neonates in her duty shift, thus the researcher insure the credibility of oxygen recording sheets.

The way for monitoring was first started when baby putted in supine position, the $\mathrm{O}_{2}$ saturation was recorded during 30 minutes for exactly 2 hours in that position. On second time $\mathrm{O}_{2}$ was recorded by putting the same baby on prone position (abdomen on basinet and head lateral), and $\mathrm{O}_{2}$ saturation were recorded every 30 minute till 2hours, the data was collected for all preterm neonates whatever the kind of $\mathrm{O}_{2}$ therapy they had received, either ventilation supports, nasal CPAP, or oxygen supports by nasal canula.

Pulse oximeter was used to assess oxygenation of preterm neonate as data collection tool, it is non-invasive technique that could show the hypoxic changes, and it had a sensitivity of 0.92 and specificity of 0.90 .in recording oxygen saturation [8]. During changing the infants' position, the neonates with high body temperature were excluded that because the body temperature may affects oxygen saturation.

Furthermore, the data was first established by measuring the saturation for maximum 2hours, during that the nurse was monitoring and recording for each reading at least every $15 \mathrm{~min}$, to ensure the accuracy of this reading if there were any changes for the probe and the oximeter reading. The infants' demographic data that was obtained by the questioners (gestational age and gender, body weights, type of $\mathrm{O}_{2}$ supports) were also confirmed from their files.

\section{Results}

A total of 30 preterm's mean of gestational age 31 . 13weeks, age range (26-35) weeks, and range of body weights (800-1900kg). About $60 \%$ of this neonates were male preterm and $40 \%$ were female preterm neonate, the babies who conducted on nasal canula were 33\%, 27\% were on nasal CPAP, and $40 \%$ were on ventilation supports.

At the end of the last hour of supine position, $\mathrm{O}_{2}$ saturation mean with SD $(96.3+1.5)$ and at the end of last hour on prone position was $(98.5+1.5)$. The results of independent sample t test revealed that there is significant differences between prone and supine where newborn in prone position showed more increase in $\mathrm{O}_{2}$ saturation $(\mathrm{t}=4.35, \mathrm{p}<.05)$.

\section{Discussion}

Placement of patients with respiratory distress syndrome RDS in prone position (head lateral and abdomen on basinet) that followed supine position for two hours had shown an improvement in oxygen saturation despite that no global consensus reveled prone position in preterm's babies with RDS shorter or equal time of supine position had clinically improved oxygen saturation.

Also, Cochrane systematic reviewed studies showed that no evidence of exacting body positions of the neonate with mechanical ventilation are effective in producing clinically 
oxygen saturation improvements [9].

In this study placement of preterm's neonates with respiratory distress syndrome RDS in prone position that followed supine position for two hours had shown an improvement in oxygen saturation, this was similar of Lestari, et al. [10] study that showed quarter turn from prone position median was 94\%, and after two hours of intervention was $96.5 \%$ among twenty premature babies with RDS receiving nasal CPAP with $25-40 \% \mathrm{fiO}_{2}$.

However, there was no enough evidences showed the exact duration that improves oxygen saturation in comparing that to adult [11]. The study of Shanker, et al. which showed that the prone position improves oxygenation as compared to supine position in one hundred ventilated neonates with respiratory distress, who were reserved in supine position for three hours after all necessary resuscitative measures, after that they were kept in prone position for six hours. The result of $\mathrm{PaO}_{2}$ of all neonates increased by about $7 \%$ and the supine position, it was $86.4+5.7$ and in prone $93.5+4.1$ with $p$ value of $<0.001$ which is statistically significant.

While a study of Das, et al. [12-15] showed prone position improves oxygen saturation and decreases respiratory distress as compared to supine position in one hundred neonates with oxygen hood; mean and SD 84.84+4 in supine position and within 2 hour in prone position saturation was $91.05+3.29$, after 4 hour $91.62+3.89$ and after 6 hours it was $92.63+3.02$ respectively with $\mathrm{P}$ value of $<0.001$ which is statistically highly significant.

\section{Conclusion}

Since the effect of prone positions on oxygen saturation are controversial, this pilot study showed that the prone position for 2 hours duration, had an effect on Jordanian preterm neonates diagnosed with respiratory distress syndrome, wither they are on oxygen support or not ,comparing that to supine position.

The researcher needs larger samples to generalize this conclusion, and to be more specific in describing the appropriate position, and clarifying the settings of this maneuver.

\section{References}

1. Sweet DG, Carnielli V, Greisen G, Hallman M, Ozek E, et al. (2017) European consensus guidelines on the management of respiratory distress syndrome-2016 update. Neonatology 111(2): 107-125.

2. Batieha AM, Khader YS, Berdzuli N, Chua-Oon C, Badran
EF, et al. (2016) Level, causes and risk factors of neonatal mortality, in Jordan: results of a national prospective study. Matern Child Health J 20(5): 1061-1071.

3. EuroNeoStat Annual Report for Very Low Gestational Age Infants 2010. The ENS Project. Hospital de Cruces, Unidad Neonatal 5-D, Plaza de Cruces s/n, 48903 Barakaldo, Spain.

4. Kallet RH (2015) A comprehensive review of prone position inARDS. Respiratory care 60(11): 1660-1687.

5. Ghorbani F, Asadollahi M, Valizadeh S (2013) Comparison the effect of sleep positioning on cardiorespiratory rate in noninvasive ventilated premature infants. Nurs Midwifery Stud 2(2): 182-187.

6. Bhat RY, Hannam S, Pressler R, Rafferty GF, Peacock JL, et al. (2006) Effect of prone and supine position on sleep, apneas, and arousal in preterm infants. Pediatrics 118(1): 101-107.

7. Modesto IF, Avelar AF, Pedreira Mda L, Pradella-Hallinan M, Avena MJ, et al. (2016) Effect of sleeping position on arousals from sleep in preterm infants. J Spec Pediatr Nurs 21(3): 131-138.

8. Lee WW, Mayberry K, Crapo R, Jensen RL (2000) The accuracy of pulseoximeterin the emergency department. The American journal of emergency medicine 18(4): 427-431.

9. Rivas-Fernandez M, Roqué I Figuls M, Diez-Izquierdo A, Escribano J, Balaguer A (2016) Infant position in neonates receiving mechanical ventilation. Cochrane Database of Systematic Reviews (11).

10. Lestari P, Susmarini D, Awaludin S (2018) The Effect of Quarter Turn from Prone on Oxygen Saturation among Premature Babies with Respiratory Distress Syndrome. Jurnal Keperawatan Soedirman 13(1): 38-44.

11. Bloomfield R, Noble DW, Sudlow A (2015) Prone position for acute respiratory failure in adults. Cochrane Database of Systematic Reviews (11).

12. Das H, Shaikh S, Kella N (2011) Effect of prone versus supine position on oxygen saturation in patients with respiratory distress in neonates. Pakistan Journal of Medical Sciences 27(5).

13. Brunherotti MA, Martinez FE (2013) Response of oxygen saturation in preterm infants receiving rib cage stabilization with an elastic band in two body positions: a randomized clinical trial. Brazilian journal of physical therapy 17(2): 105-111. 
14. Ghafoor T, Mahmud S, Ali S, Dogar SA (2003) Incidence of respiratory distress syndrome. J Coll Physicians Surg Pak 13(5): 271-273.
15. Lal S, Abassi AS, Lal S, Jamro S (2013) Effects of position on oxygen saturation in acute respiratory distress in neonates. Int J Surg Pakistan 18(4): 5-9. 